\title{
The Challenges Faced By Educators in Online Teaching during the Covid-19 Pandemic Outbreak
}

\author{
${ }^{1}$ Sarah Sabir Ahmad* \\ Faculty of Business and Management \\ Universiti Teknologi MARA (UiTM), Malaysia \\ ${ }^{2}$ Mhd Azmin Mat Seman \\ Department of Civil Engineering \\ Politeknik Sultan Abdul Halim Mua'dzam Shah, Malaysia \\ ${ }^{3}$ Azfahanee Zakaria \\ Faculty of Business and Management \\ Universiti Teknologi MARA (UiTM), Malaysia \\ *Corresponding author: \\ Email: sarah342@uitm.edu.my
}

\begin{abstract}
Since the pandemic attack the whole world, various research has been conducted related to the challenges of online learning. Focus has always been on the issues faced by the students, but lack of research has been to done from the educators' perspective. Therefore, this research aims to identify the issues and challenges faced by the educators in online teaching. The issues that the researchers identified are technology, lack of training and lack of tools and materials make it difficult for the educators to adapt with the changes from teaching in the physical classroom to a virtual classroom which exposes the educators to a new teaching environment and this imposed countless challenges. The research method that is used in this research is simple random sampling where the sample size of this study is around 30 educators which focus on the educators that engage in online teaching at the age range between 21 years old until 60 years old. The data was collected through a questionnaire and the questionnaire is divided into three different sections. The data analysis procedure used in this research is frequency analysis to offer the researcher to analyze the data of the questionnaire. It was identified majority of the respondents are facing challenges with online teaching which decrease their motivation and productivity and contribute to low satisfaction and outcomes in their delivery of lectures.
\end{abstract}

Keywords: Educators; Online Teaching; Challenges; technology; training

\section{INTRODUCTION}

Online learning is on the upsurge due to the current pandemic situation, but educators are still feeling left behind, and they seem to not have enough support in online teaching (Abdul Halim Abdullah, (2020). Since March 2020 the world's education sectors have drastically changed their traditional face to face teaching method to online platforms as almost all countries shut down the schools and universities to break the chain of the virus. In Malaysia, all curriculum and cocurricular activities in education involving mass gathering needed to be abolished temporarily to create social distance and ensure safety of all students and teachers (Yusri Muzamir and Amin Jali (2020), Abdul Halim Abdullah, (2020)). 
It has been a challenging period of time for all the educators at all levels to adapt to it and there is still no clear indication when things will return to normal. Research has always highlighted the hardships of online learning for the students. However, many fail to identify that in reality the educators also face many great hurdles. Educators themselves must learn new ways to organize their lessons and learn how to work with new materials and platforms in order to be successful when teaching online. Twenty-first-century teachers need skills to develop lessons for traditional classroom instruction while also applying them to digital teaching environments (The Resilient Educator, 2020).

Online teaching appears to be a suitable alternative to replace traditional classroom education since the pandemic's outbreak. Technology has brought in a complete transformation in education. Twenty-first-century teachers need skills to develop lessons for traditional classroom instruction while also applying them to digital teaching environments (The Resilient Educator, 2020). Online education may not provide the same level of support that traditional classroom education offer, therefore we need to understand that this had led to major challenges for educators to go through this online teaching. It is important to understand teachers as they are the group of people charged with teaching, training, encouraging, and inspiring pupils to learn (Okeke-James, Igbokwe, Anyanwu \& Obineme, 2020).

\section{BACKGROUND}

Not many research has been conducted regarding the studies on the issues and challenges that are faced among educators. Previous research on educational assessment has focused more on students and less on the role of teachers as innovators (SantiagoTejedor, 2021). But regardless that, most of these empirical studies have consistently found that almost all the educators are facing a hard time in virtual teaching at the current moment (Ismail, Ariffin, \& Abdullah, 2020). These circumstances happened due to the Covid-19 pandemic that seems endless each day. In consequence, the educators are trying their best in adapting with this new norm of using all the available technologies (Ismail, Ariffin, \& Abdullah, 2020).

Therefore this article aims to highlight the issues and challenges that are faced among educators such as technology, lack of effective training and lack of materials and tools. According to Zulkifli, Hamzah, \& Bashah (2020), issues of the adaptation to the technology is one of the main issue faced by the educators as poor accessibility especially for internet connection leads to difficulties in conducting their classes. They are also unable to reach the students because of this challenge. The second issue that this article highlights is about the lack of effective training contributes to lack of competencies in handling online classes since many of the educators are among the Generation $\mathrm{X}$ and Generation $\mathrm{Y}$ that were born between the year of 1960 s to the late 1990 s.

According to Lowell \& Jr (2018), the statistic obtained through a survey among these generations shows that $54.2 \%$ of Generation $\mathrm{X}$ and $51.9 \%$ of Generation Y do not have capability in managing the technology due to lack of training received before the pandemic happened. These individuals are usually unfamiliar with the advanced technologies that are available now such as Webex and Microsoft Teams. Also, many teachers who are using online platforms are finding it hard to adapt to new ways of teaching (Samta Jain, 2021). Samta Jain (2021) stated that online classes are proving more problematic to middle-aged 
teachers who are finding it challenging to maintain discipline in the class and are subject to online bullying and harassment from students. Not all educators are familiar with the technology being used during this pandemic. Some teachers are at present comfortable with the use of technology, while others rarely used online teaching tools to direct student learning in the traditional face-to-face classroom (Nasr, 2020). Due to the limited training that they received beforehand of the pandemic, it is causing an extensive issue to these educators in applying the online teaching.

Additionally, the third challenge disclosed is regarding the lack of materials and tools in online teaching (Zulkifli, Hamzah, \& Bashah, 2020). Educators are having this issue because they are lacking of teaching materials that can be used during the online classes and also insufficiency of tools such as screen recording software or learning management system that they can use (Gurung, 2021). Gurung (2021) also stated that the educators need to adjust themselves with the challenges and also need to maintain the quality of teaching as the parents of the student will have the same expectation from the educators to educate their children no matter what type of platform they will be using or how they will teach the students. Therefore, the finding of this study is very imperative to notify the government, schools and authorities as well as practitioners that this group of people (educators) are also facing major challenges and drawbacks in conducting online teaching and learning.

\section{Issues in Technology}

Virtually, all teachers faced the incredible challenge of moving from traditional in-person teaching approaches to person that depend on technological proficiency, inventive ways of evaluation, and neglected approaches of care. Teachers had no choice but to acquire the technology. Some teachers were already familiar with technology, while others had little experience with it and just knew teaching in the traditional face-to-face teaching to direct student learning (Nasr, 2020). Thus, teachers expressed their dissatisfaction with the difficulty of having constant access to the internet. Several research investigations have identified a few factors that contribute to a lack of technological access. According to several studies, teachers are unable to integrate new technology due to a lack of resources, particularly home access (Ghavifekr, Kunjappan, Ramasamy \& Anthony, 2020). It is clear that low internet or Wi-Fi coverage is the major challenge to teaching and learning using MOOC (Norfarahi, Mohd Isa \& Nur Hazeleen, 2020). Internet access is important in online teaching and learning. In both synchronous and asynchronous situations, access to the Internet is essential for online teaching and learning (Shaharudin, Halimaton \& Zul, 2020).

\section{Lack of Effective Training}

Teaching on an online platform is challenging for some teachers because they still lack the necessary abilities in the usage of information technology to be able to present educational materials online (Anuar, Haslindar, Tunku \& Simin et. al., 2020). The lack of effective training is the top mentioned problem in the literature (Simin, Thanusha, Logeswary \& Annreetha, 2020). The issue of how teachers' competence and opportunities in learning digital skills contribute to teachers' understanding of the challenges of the specific situation also comes out (Johannes, 
Daniela \& Nina, 2020). There are also 16 to 20 percent of teachers who believe they lack enough digital training, expertise, and awareness of digital tools and applications. Moreover, teachers in both public and private schools have largely responded in the same way (Samta, Marie \& Anviti, 2020). The most three obstacles to teachers using ICT are a lack of training (Beggs, 2000). According to research from Turkey, the biggest issue in applying modern ICT in education is a lack of any in teacher training (Ozden, 2007). The lack of training is absolutely complex, as it is necessary to examine numerous factors in order to ensure that training is effective. The use of ICT in initial teacher training, as well as time for training, pedagogical training, and skills training, were all on the list (Becta, 2004). If a teacher combines knowledge of the subject's unique content with knowledge of pedagogical techniques for teaching it and understanding of ICT use, he or she may provide a high-quality e-learning education (Santiago, Laura, Ana, Fernanda \& Alberto, 2021).

\section{Lack of Tools and Materials}

Before utilizing online teaching, some teachers require more preparation with teaching materials. Teachers must now teach through online pedagogical and evaluation methods, which means they must enhance the use of technology tools in their teaching aids (Sueraya, Khadijah, Sabrina, Arifin \& Nurazzelena, 2021). There are some findings on the challenges of teaching and learning using MOOC, which the challenges are including that material in the MOOC course is not interesting and boring, and also the incomplete equipment in using MOOC (Norfarahi, Mohd Isa \& Nur Hazeleen Bashah, 2020). Teachers may be lacking in tools such as screen recording software, video conferencing apps, cloud services, and other tools needed to communicate with students, construct courses, and upload or cast information. Moreover, the majority of dependable tools are either paid services or require a subscription. Therefore, the vast majority of teachers have backed away from free services and trial software, which may come with several restrictions on usage and trial periods (Mohamed Hassan, 2021). Teachers and students must be encouraged to use digital tools, regardless of the need for technological infrastructure to integrate ICT in teaching methods (Johannes, Daniela \& Nina, 2020).

\section{METHOD}

\section{Sample and Population}

The population of educators which included primary and secondary teachers in Peninsular Malaysia. The age range of these educators basically is between 21 years old until 60 years old. Additionally, the sampling method that is used in this study is simple random sampling. According to the (Sharma, 2017), simple random sampling is an unbiased random selection, and it is also considered as a fair way of selecting a sample from a given population since every member is given equal opportunities of being selected. Moreover, this type of sampling also offers the most generalizability rather than the others sampling. Next, due to time constraint and limited movements, the sample size for this study is 100 educators. The reason is as stated by Sekaran (2018), to obtain a normal distribution a number of minimum 
30 respondents need to be selected as the respondents of the study. Therefore, with that in mind, 100 respondents were selected as the sample of this study.

\section{Data Collection Method and Analysis Procedure}

The data was collected through a questionnaire that was formulated by the researcher from adaption of previous research. The researchers choose to do the questionnaire because it is the lowest cost option, can be expanded to the geographical coverage and perceived as more anonymous. In the questionnaire, the section was divided into three different issues. The first details that the researcher asked the participants is their demographics data then continued with sections for every challenges faced by the educator which are technology, training and material and tools used by them.

Due to the nature of this study which is descriptive, dichotomous scale was used where the scale elicit a Yes or No answer. The researcher decided to use the dichotomous scale because it can offer the researcher the description of what are the relevant challenges faced by the educators.

Frequency analysis was used to analyze all the data which include the demographic section, technology section, training effectiveness section and material and tools section. Based on the (Winter, 2016), frequency analysis is a descriptive statistical method that shows the number of occurrences of each response chosen by the respondents. The frequency analysis is the best method to be used as it offers the researcher to analyze the data of the questionnaire and it helps the researcher to organize and summarize the survey data in a tabular format. The reason why this data analysis procedure was chosen is because it is simple and fast. Other than that, the frequency analysis is being used to help reduce the time constraints as the researcher acknowledges that questionnaires that formulate only contain 'Yes' and 'No' answers which help to reduce the time taken for each of the respondents to respond to the questionnaire.

\section{ANALYSIS FINDINGS AND DISCUSSION}

From the 100 questionnaires sent, only 33 questionnaires were usable. This indicate a response rate of $33 \%$ only. The demographic results identified the majority of the respondents are aged between 51 to 60 years old with 12 respondents while the least respondents are from them aged 41-50 years old with only 5 respondents. Also, based on the results from questionnaires to educators around Malaysia, the highest state responded is from Pulau Pinang. It can be seen that Pulau Pinang led with 11 respondents and followed by Kedah and Perak with 5 respondents respectively and then followed with 4 respondents each from Terengganu and Johor. Meanwhile, Selangor only has only one feedback from the questionnaires. 


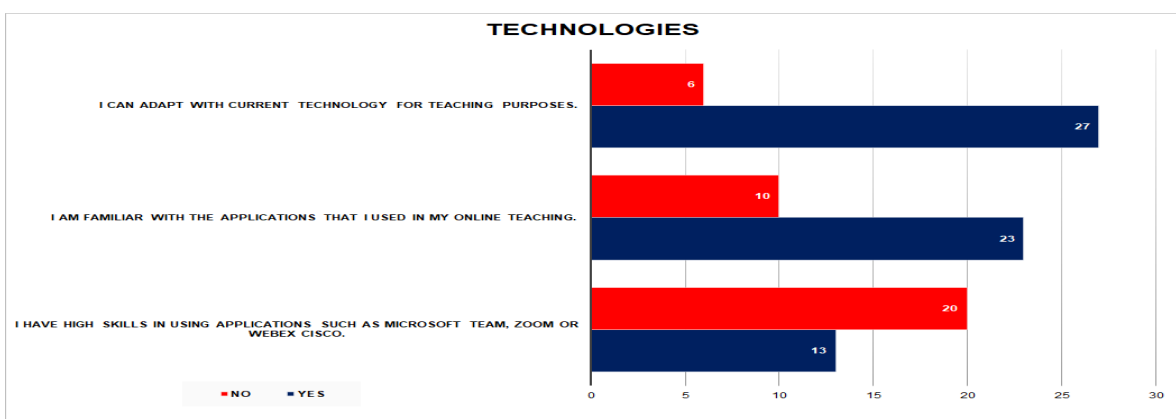

Figure 1. The technology's awareness among educators

This part of the survey tested the technology exposure among educators. It shows that the majority of the output is positive. It is stated that most of them can adapt with the current technology changes with 27 of them responding "yes" in the questionnaires and 23 of them responding that they are familiar with all the applications available to ease them in teaching students online.

However, 20 of the educators responded that they did not have high skills in using online applications. Even though they did not have high skills using the applications, they still can perform online teaching. It is undeniable that the medium of technology has become the main platform for connecting educators and students. Moreover, in order to keep pace with the current generation, educators need to be aware and technologically literate so as not to be left behind. Even though they come from the Baby boomers generation, Generation $\mathrm{X}$ and $\mathrm{Y}$, they are still determined to learn technology to connect with students.

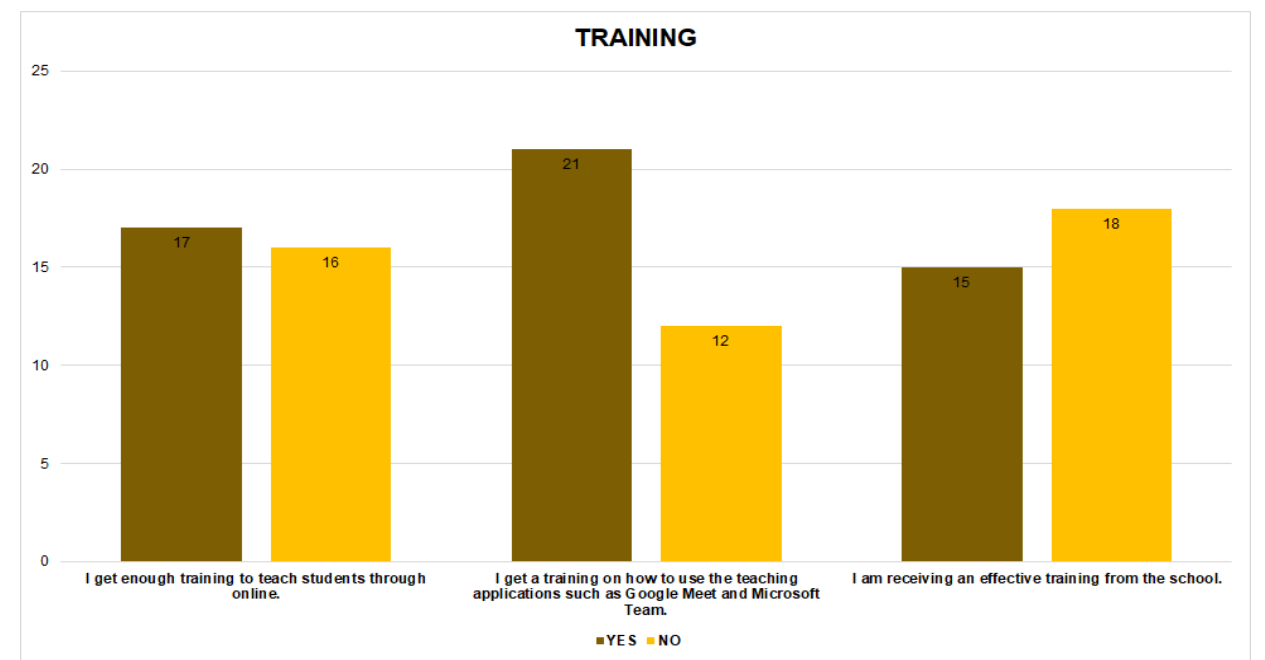

Figure 2. The questions regarding training to educators

This part discusses training for educators. Training is necessary to inform educators with current information and knowledge needed for them to face these new norms of teaching. 17 out of 33 educators stated that they did not get enough training to teach students online and they claimed that they did not get effective training in order to give the best for the student using the online platforms (18 respondents). It is understandable as the education system faces sudden changes that make the school have limitations in providing training required for all educators. 
However, the good part is they still get training on how to use the basic platforms like Zoom, Webex Cisco and Google Meet, which can be concluded that they still can perform teaching but not as effective as they expected.

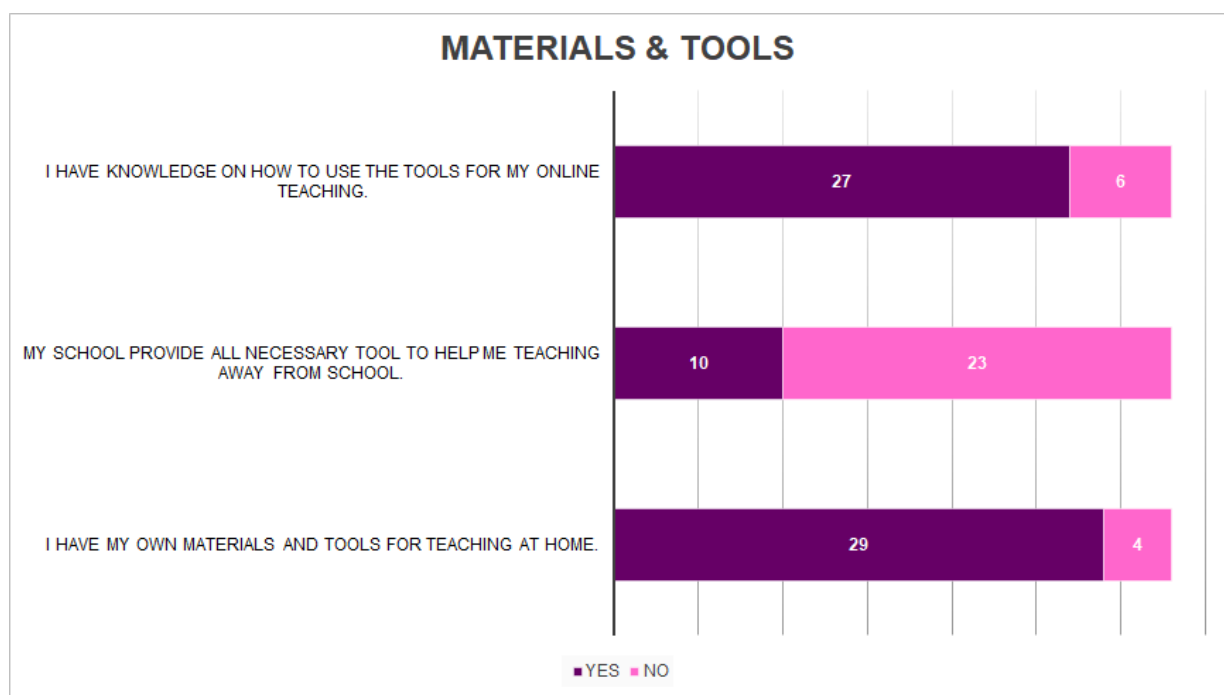

Figure 3. The results regarding materials provided for educators

The results from this part highlighted the teaching materials for the educators. On the positive side of the result it shows that they have the knowledge to use the tools for online teaching and the majority of them, 29 respondents, stated that they have their own materials and tools for them to teach even though they are at home. This demonstrates an educator's determination to ensure that students receive the same knowledge as in the classroom.

However, 23 respondents claimed that the school did not provide necessary tools to help them to teach at home. It is challenging for them as they need to find it by themselves and it is time consuming as they cannot totally focus at home. Therefore, these problems need to be taken as serious matters to make sure education can be carried on effectively and efficiently.

\section{CONCLUSION}

In conclusion, there are many educators who are facing variety of issues and challenges in online teaching during this difficult pandemic situation. These issues and challenges not just can decrease the motivation and productivity of the educators but also contribute to the poor satisfaction and outcomes in teaching to the students. Additionally, the findings have identified that the educators are facing with massive issues related to their adaption to the new norm of teaching styles using various technologies and these particular groups have not received proper training to keep them effective and lack of materials and tools provided by the schools and government to the educator somewhat has decline their teaching ability and productivity.

These issues are basically because of unpreparedness of the government, schools, authorities as well as the educators to face the pandemic, because it happen so suddenly, and created many chaos in the teaching and learning environment. Extra effort in teaching and learning of how to use a certain software that is used in 
online teaching should be the effort of all the parties involved. Besides, authorities involved need to assist with providing online materials and tools to ease the educators and students teaching and learning experience. With that, it is hope to deem some light to ease the process of teaching a learning as online learning is here to stay.

This study is like any other studies has its potential limitations in which the results that gained from the survey made among the educators may be biased and the methods used might be surface. On the whole, the future researchers should consider applying more in-depth methodology in analyzing this issue for a better result as well getting more respondent to improve the findings as a whole. Therefore it is hope the findings for future studies can be improved based on this research's effort in identifying the challenges faced by the educators during the pandemic outbreak.

\section{Acknowledgements}

Thank you to the team Anizah binti Abdullah, Khairun Nisaa binti Abd Rahim, Nor Shakinah binti Aminuddin and Siti Nur Najwa binti Zulkifli for conducting the data collection stage, literature review search and analysis. The effort and time dedicated in completing this paper is greatly appreciated.

\section{REFERENCES}

Becta (2004). What the research says about using ICT in Geography? Coventry: Becta.

Beggs, T. A. (2000). Influences and barriers to the adoption of instructional technology. Paper presented at the Proceedings of the Mid-South Instructional Technology Conference, Murfreesboro, TN.

Hassan, M. (2021). Online Teaching Challenges during COVID-19 Pandemic. International Journal of Information and Education Technology.

Johannes König, D. J.-B. (2020). Adapting to online teaching during COVID-19 school closure: teacher education and teacher. European Journal of Teacher Education.

Nasr, N. (2020). Teachers as Students: Adapting to Online Methods of Instruction and Assessment in the Age of COVID-19. Electronic Journal for Research in Science and Mathematics Education.

Norfarahi Zulkifli, M. I. (2020). Challenges to Teaching and Learning Using MOOC. Scientific Research Publishing.

Ozden, M. (2007). Problems with science and technology education in Turkey. Eurasia Journal of Education, 3(2), 157-161.

Samta Jain, M. L. (2021). Teachers' Voices on the Impact of COVID-19 on School Education: Are Ed-Tech Companies Really the Panacea? Contemporary Education Dialogue, 64-69.

Santiago Tejedor, L. C.-E. (2021). Higher Education Response in the Time of Coronavirus: Perceptions of Teachers and Students, and Open Innovation. Journal of Open Innovation. 
Sareen, S., \& Anita Nangia. (2020). Online Teaching during COVID 19: Attitude and Challenges faced by School Teachers. International Journal of Disaster Recovery and Business Continuity, Volume 1, 3102-3018.

Sekaran, U. (2018). Research Methods for Business: A Skill Building Approach. United Kingdom: Wiley Publisher.

Sharma, G. (2017). Pros and cons of different sampling techniques. International Journal of Applied Research, 749-752.

Sicilia, C. (2005). The Challenges and Benefits to Teachers' Practices in Constructivist Learning Environments.

Simin Ghavifekr, T. K. (2020). Teaching and Learning with ICT Tools: Malaysian Online Journal of Educational Technology.

Sueraya Che Haron, K. K. (2021). Challenges Faced by Teachers in Online Teaching during the. Journal of Education and Practice.

Tushar Gupta, \& Abha Shree. (2020,). Online Teaching-Learning in Higher Education during Lockdown Period of COVID-19 Pandemic. International Journal of Educational Research Open, Volume 1.

Winter. (2016). Division of Information Technology Services. calstatela.edu, 1-18. 